\title{
Endoscopic Band Ligation for Rectal Dieulafoy's Lesion: Serial Endoscopic Images
}

Y. Mizukami ${ }^{1}$, K. Akahoshi ${ }^{1}$, N. Kondoh ${ }^{1}$, N. Harada ${ }^{2}$, H. Nawata ${ }^{1}$

${ }^{1}$ Department of Gastroenterology, Aso Iizuka Hospital, Iizuka, Japan

2 Third Department of Internal Medicine, Faculty of Medicine, Kyushu University, Fukuoka, Japan

\section{Corresponding Author}

K. Akahoshi, M.D., Ph.D.

Department of Gastroenterology

Aso lizuka Hospital

3-83 Yoshio

lizuka 820-8505

Japan

Fax: $\quad+81-948-298747$

E-mail: kakahoshih1@aih-net.com

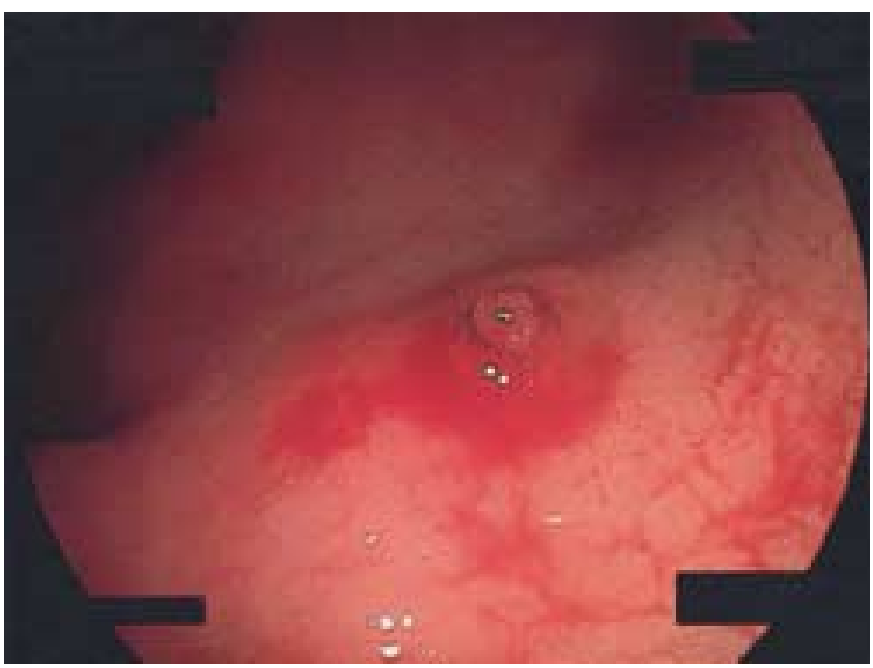

Figure 1 An 85year-old Japanese woman with rectal Dieulafoy's lesion presented with fresh blood hematochezia. Colonoscopy revealed a $5 \mathrm{~mm}$ shallow mucosal defect with an exposed vessel in the anterior wall of the lower rectum.

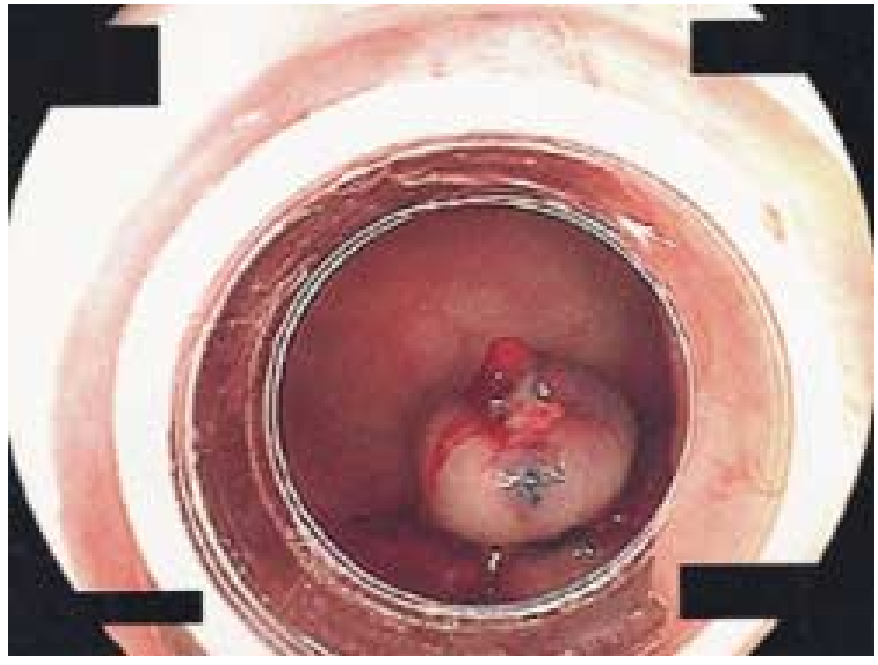

Figure 2 A gastroduodenoscope with an attached singleband ligator was employed, and $4 \mathrm{ml}$ of hypertonic saline epinephrine solution was injected beneath the lesion. After endoscopic band placement, the hemorrhage stopped completely. Note that the Dieulafoy's lesion had been wholly encased by the band.

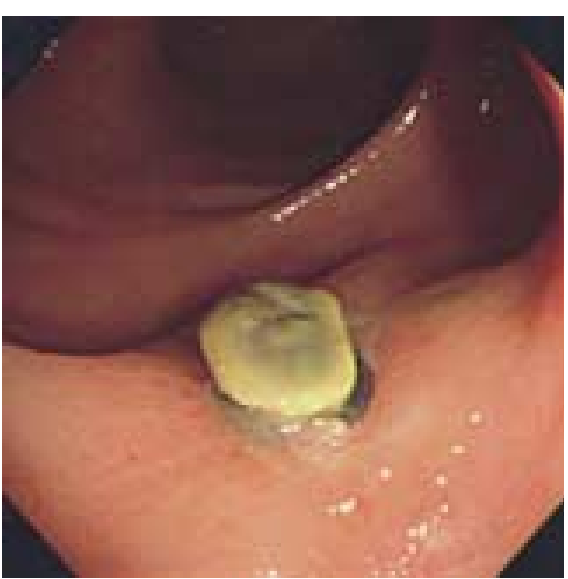

Figure 3 Endoscopy at 1 week after the procedure revealed a $10 \mathrm{~mm}$ wide shallow ulcer at the site of the lesion. The O-ring remained on the ulcerated lesion.

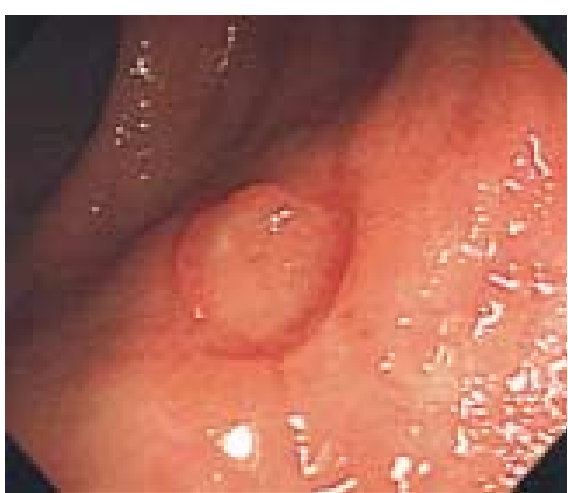

Figure 4 Follow-up colonoscopy (at 2 weeks) showed an ulcer scarring. No further bleeding has occurred during 6 months of follow-up. 